\title{
A role of electrons in zirconium oxidation
}

\author{
Pavel N. Alekseev and Alexander L. Shimkevich* \\ NRC Kurchatov Institute, 1, Kurchatov Sq., Moscow 123182, Russia
}

Received: 22 April 2016 / Received in final form: 26 April 2017 / Accepted: 29 May 2017

\begin{abstract}
Growing the oxide scale on the zirconium cladding of fuel elements in pressured-water reactors (PWR) is caused by the current of oxygen anions off the waterside to the metal through the layer of zirconia and by the strictly equal inverse electronic current. This process periodically speeds up the corrosion of the zirconium cladding in the aqueous coolant due to the breakaway of the dense part of oxide scale when its thickness reaches $2 \mathrm{mkm}$. It is shown that the electronic resistivity of zirconia is not limiting the zirconium oxidation at working temperatures. For gaining this limitation, a metal of lesser valence than zirconium has to be added to this oxide scale up to $15 \%$. Then, oxygen vacancies arise in the complex zirconia, increase its band-gap, and thus, sharply decrease the electronic conductivity and form the solid oxide electrolyte whose growth is inhibited in contact with water at working temperatures of PWR.
\end{abstract}

\section{Introduction}

Zirconium alloys are used for fuel cladding in pressuredwater reactors (PWR), thanks to a low capture crosssection of thermal neutrons, the good corrosion resistance in water at high temperatures and to the mechanical properties [1]. However, the mechanism of zirconium oxidation is not understood so far despite the great number of experiments carried out during the last 40 years over studying the oxidation of zirconium alloys in the aqueous coolant [2-7]. There is no consensus so far over mechanisms of oxidation of metals in water [8] though this information is very important for developing a new cladding material of fuel elements for PWR.

\section{Electrons in $\mathrm{ZrO}_{2-x}$}

The stoichiometric zirconium dioxide $(x=0)$ without impurities is a single stable oxide of zirconium with ionic bond of atoms which has $\varepsilon_{\mathrm{g}} \sim 4.0 \mathrm{eV}$, and $\chi_{\mathrm{o}}=4.0 \mathrm{eV}[9,10]$.

The oxidation of zirconium in PWR coolant according to electrochemical reactions

$$
\begin{gathered}
\mathrm{Zr} \rightarrow \mathrm{Zr}^{4+}+4 \mathrm{e}^{-}, \\
4 \mathrm{e}^{-}+2 \mathrm{H}_{2} \mathrm{O} \rightarrow 2 \mathrm{O}^{2-}+2 \mathrm{H}_{2} \uparrow, \\
\mathrm{Zr}^{4+}+2 \mathrm{O}^{2-} \rightarrow \mathrm{ZrO}_{2},
\end{gathered}
$$

\footnotetext{
* e-mail: shimkevich_al@nrcki.ru
}

is carried out by generating electrons on the interface, $\mathrm{Zr}(\mathrm{O}) / \mathrm{ZrO}_{2-x}$, over the reaction (1), by their passing through oxide scale to the interface, $\mathrm{ZrO}_{2} / \mathrm{H}_{2} \mathrm{O}$, for disintegrating water over the reaction (2), and by diffusion of oxygen anion back to the metal through two different oxide layers (see Fig. 1) for oxidizing zirconium over the reaction $(3)$. Then, the total reaction is

$$
\mathrm{Zr}+2 \mathrm{H}_{2} \mathrm{O} \rightarrow \mathrm{ZrO}_{2}+2 \mathrm{H}_{2} \uparrow
$$

One can see that the first layer, $\mathrm{ZrO}$, is the source of electrons for the second, $\mathrm{ZrO}_{2-x}$, due to disintegrating zirconia over the reaction:

$$
0 \rightarrow \mathrm{V}_{\mathrm{O}}^{2+}+2 \mathrm{e}^{-}+(1 / 2) \mathrm{O}_{2} \uparrow
$$

when the oxidation potential, $\left(k_{\mathrm{B}} T / 4\right) \ln P_{\mathrm{O}_{2}(\mathrm{Zr})}$, is expressed by a correspondent partial oxygen pressure of zirconia dissociation [12]

$$
\ln P_{\mathrm{O}_{2}(\mathrm{Zr})}=-11.3 / k_{\mathrm{B}} T+19.9 .
$$

The oxide scale on zirconium has relatively high density of electrons as well as the density of oxygen vacancies. However, the electronic conductivity in $\mathrm{ZrO}_{2-x}$ film exceeds the anionic one which allows oxidizing of zirconium by oxygen anions diffusing over zirconia vacancies [13].

Thermodynamics of the reaction (5) can be expressed by the following dependence [14]:

$$
\varepsilon_{\mathrm{F}}=\mu_{\mathrm{o}}-\mu_{\mathrm{v}}(x) / 2-\left(k_{\mathrm{B}} T / 4\right) \cdot \ln P_{\mathrm{O}_{2}},
$$




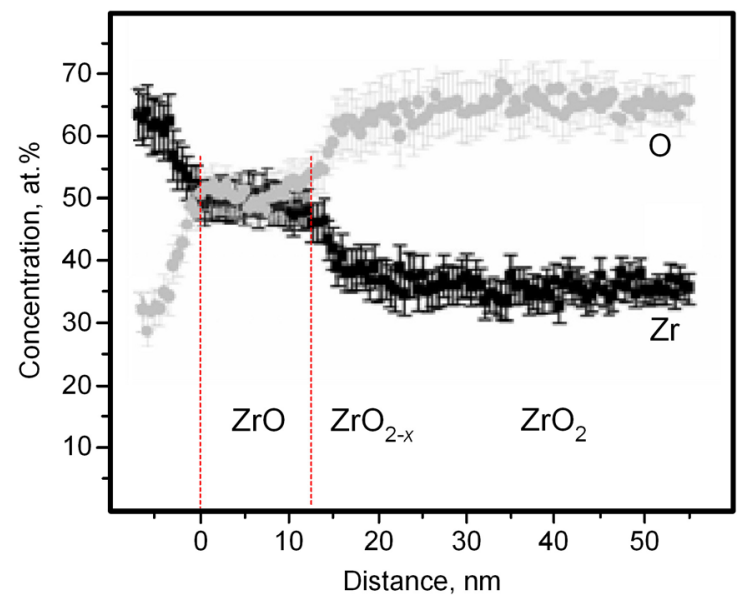

Fig. 1. The composition profile of dense part of the oxide scale $(\leq 2 \mathrm{mkm}[11])$ on the surface of Zircaloy-4 (SRA) taken across the metal/oxide interface after 90-day testing in liquid water heated up to $360^{\circ} \mathrm{C}$ [1]; the dotted vertical lines separate "black zircon", $\mathrm{ZrO}$, from zirconium and dense hypo-stoichiometric zirconia, $\mathrm{ZrO}_{2-x}$.

where the electrochemical potential of oxygen vacancies is expressed by the equation of ideal solution

$$
\mu_{\mathrm{v}}(x)=k_{\mathrm{B}} T \cdot \ln [x /(1-x)],
$$

and $[15,16]$

$$
\mu_{\mathrm{o}}(T)=-5.10+0.29 k_{\mathrm{B}} T .
$$

Then, it is easy to define Fermi level, $\varepsilon_{\mathrm{F}}$, in zirconia on the interface $\mathrm{Zr} / \mathrm{ZrO}_{2-x}$ using the equations (6)-(9). This level is shown in Figure 2.

One can see that in zirconia contacting zirconium, Fermi level is shifted off the middle of band-gap to the conduction band where quasi-free electrons (full blue line in Fig. 2) appear [17]. Their molar concentration $\left[\mathrm{e}^{-}\right]$is given by Fermi-Dirac statistics, which can be simplified to Maxwell-Boltzmann one [18]:

$$
\left[\mathrm{e}^{-}\right]=N_{\mathrm{A}} \cdot \exp \left[\left(\varepsilon_{\mathrm{F}}-\varepsilon_{\mathrm{c}}\right) / k_{\mathrm{B}} T\right] .
$$

It follows that

$$
x=x_{\mathrm{o}}+(1 / 2) \cdot \exp \left[\left(\varepsilon_{\mathrm{F}}-\varepsilon_{\mathrm{c}}\right) / k_{\mathrm{B}} T\right],
$$

and

$$
\left[\mathrm{V}_{\mathrm{O}}^{2+}\right]=N_{\mathrm{A}} \cdot x_{\mathrm{O}}+\left[\mathrm{e}^{-}\right] / 2 .
$$

Substituting (6), (8), (9), and (11) in (7), we find the first boundary condition

$$
\varepsilon_{\mathrm{Fz}}=-2.19-2.87 k_{\mathrm{B}} T,
$$

in the oxide scale contacting zirconium cladding and the second

$$
\varepsilon_{\mathrm{Fw}}=-3.72+0.92 k_{\mathrm{B}} T,
$$

in the oxide scale contacting water whose oxidation potential can be expressed by the equivalent oxygen pressure [11]

$$
\ln P_{\mathrm{O}_{2}(\mathrm{w})}=-5.53 / k_{\mathrm{B}} T+20.7 .
$$

Equations (14) and (15) define the variation of the concentrations (10) and (12) in the dense part of oxide scale from $10^{21}$ to $10^{10} \mathrm{~mol}^{-1}$ for electrons and from $5 \times 10^{20}$ to $6 \times 10^{18} \mathrm{~mol}^{-1}$ for oxygen vacancies at $650 \mathrm{~K}$.

\section{The location of black zircon}

One can see in equation (11) and Figure 2 that Fermi level in $\mathrm{ZrO}_{2-x}$ is equal to $-2.31 \mathrm{eV}$ in contact with zirconium at $650 \mathrm{~K}$. Thus, $\chi=2.31 \mathrm{eV}$ for the dense part of oxide scale (DPOS) is less than $\chi_{z}=4.0 \mathrm{eV}$ for the metal [19]. Therefore, electrons pass in zirconium from $\mathrm{ZrO}_{2-x}$, recharging the metal negatively and enriching DPOS interface region by oxygen vacancies, $\left[\mathrm{V}_{\mathrm{O}}^{2+}\right]$, due to the positive $\Delta_{\mathrm{dl}}$ :

$$
\Delta_{\mathrm{dl}}=\left(\chi_{\mathrm{z}}-\chi\right) / \mathrm{e}=1.69 \mathrm{~V} .
$$

The $\left[\mathrm{V}_{\mathrm{O}}^{2+}\right]$ distribution in a diffusive part of the double electric layer ( $\mathrm{dl}$ ) is described by equation [20]

$$
\mu_{\mathrm{v}}(\varphi)-2 \mathrm{e} \varphi=\mu_{\mathrm{v}}(0) .
$$

Substituting (8) in (17), we obtain $x_{\mathrm{dl}}$ at the oxide side of $\mathrm{Zr} / \mathrm{ZrO}_{2-x}$ interface:

$$
x_{\mathrm{dl}}=\left[1+x_{\mathrm{o}}^{-1} \exp \left(-\Delta_{\mathrm{dl}} / k_{\mathrm{B}} T\right)\right]^{-1} \sim 1,
$$

i.e. the "black zircon", $\mathrm{ZrO}$ shown in Figure 1 [1]. The thickness of this layer is defined by Debye length $L_{\mathrm{D}}=\left(k_{\mathrm{B}} T / 4 \pi \mathrm{e}^{2} n_{\mathrm{v}}\right)^{1 / 2}$ which is less than $10 \mathrm{~nm}$ [13].

The investigation of DPOS on zirconium cladding by analytic tools $[2,3]$ has disclosed $\mathrm{ZrO}$ phase between metal and $\mathrm{ZrO}_{2-x}$ layer at the initial oxidation of zirconium alloys by the aqueous coolant. They have shown that the properties of "black zircon" are more similar to zirconium than to zirconia [4]. It means that the last grows at the $\mathrm{ZrO} / \mathrm{ZrO}_{2}$ interface.

\section{Growing DPOS}

The oxidation rate of zirconium in water over the reaction (2) is characterized by the following dependence on temperature [21]

$$
R=151 \exp \left(-1.47 / k_{\mathrm{B}} T\right) .
$$

Obviously, the interface of DPOS and water is the vacancies and electrons sink that arise on the other side of DPOS on contacting zirconium. Then, the sum of their specific currents $[13,22]$

$$
j_{\mathrm{e}}=u_{\mathrm{e}} n_{\mathrm{e}} \frac{d \varepsilon_{\mathrm{F}}}{d y},
$$




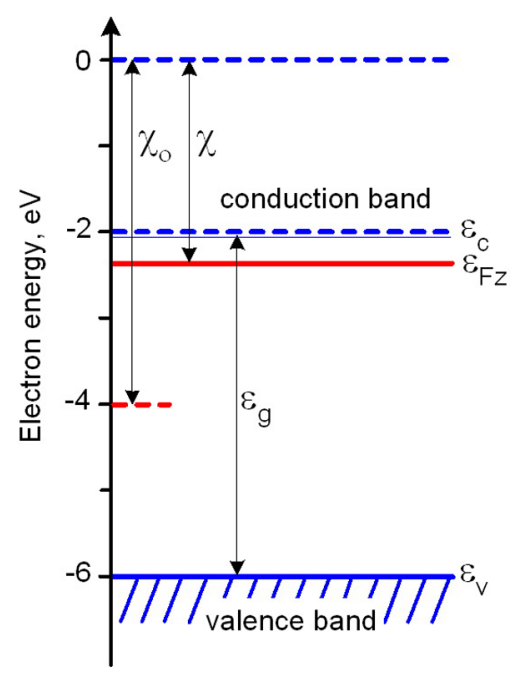

Fig. 2. The electronic band structure of $\mathrm{ZrO}_{2-x}$ with free electrons in the conduction band (full blue line) and Fermi level, $\varepsilon_{\mathrm{Fz}}$, (red line) expressed by equation (13) for $650 \mathrm{~K}$.

$$
j_{\mathrm{v}}=-u_{\mathrm{v}} n_{\mathrm{v}}\left(\frac{d \mu_{\mathrm{v}}}{d y}-2 \frac{d \varepsilon_{\mathrm{c}}}{d y}\right)
$$

is equal to zero in the range of $0 \leq y \leq h$ when $u_{\mathrm{e}} \gg u_{\mathrm{v}}$ under conditions

$$
\begin{gathered}
\frac{d j_{\mathrm{e}}}{d y}=\frac{d j_{\mathrm{v}}}{d y}=0, \\
\frac{d^{2} \varepsilon_{\mathrm{c}}}{d y^{2}}=-\alpha\left[\left(2 n_{\mathrm{v}}-n_{\mathrm{e}}\right) / K N_{\mathrm{A}}-2 x_{\mathrm{o}}\right], \\
\varepsilon_{\mathrm{c} \mid y=0}=\varepsilon_{\mathrm{c}}(0), \\
\varepsilon_{\mathrm{F} \mid y=0}=\varepsilon_{\mathrm{Fz}}, \\
\varepsilon_{\mathrm{F} \mid y=h}=\varepsilon_{\mathrm{Fw}}, \\
x_{\mid y=h}=x_{\mathrm{o}} .
\end{gathered}
$$

Substituting (20), (21), and (23) in (22), we obtain the steady-state boundary task for three functions: $x(y), \varepsilon_{\mathrm{c}}(y)$, and $\eta(y)=n_{\mathrm{e}} / K N_{\mathrm{A}}$ under boundary conditions $(24)-(27)$.

For the strong inequality: $\gamma x_{\mathrm{O}} \gg 1$ where $\gamma \equiv \alpha h^{2} / k_{\mathrm{B}} T$, we simplify the task (22)-(27) and find its solution in the form of power series:

$$
\begin{gathered}
\eta(\xi)=\sum_{k=0}^{\infty} a_{k} \xi^{k}, \\
\varepsilon_{\mathrm{c}}(\xi)=k_{\mathrm{B}} T \sum_{k=0}^{\infty} c_{k} \xi^{k},
\end{gathered}
$$

$$
x(\xi)=\sum_{k=0}^{\infty} b_{k} \xi^{k}
$$

with $\xi=y / h$. This solution implementing the equality of the specific currents (20) and (21) at any $y$ in the $\mathrm{ZrO}_{2-x}$ layer gives the expression for $R$ in the final form

$$
R=-M_{\mathrm{o}} K k_{\mathrm{B}} T u_{\mathrm{e}}\left(a_{1}+a_{0} c_{1}\right) / 8 h \mathrm{e} .
$$

Substituting (28)-(30) in (22) and (23) under boundary condition (24)-(27), we obtain

$$
\begin{gathered}
a_{1}=-a_{0}\left(1+c_{1}\right) / 2, \\
c_{1}=a_{0}(2 v-1) /\left[4 x_{\mathrm{o}}+a_{0}(v+1)\right],
\end{gathered}
$$

where $a_{0}=0.057 \exp \left(-0.19 / k_{\mathrm{B}} T\right)$ and $v=u_{\mathrm{e}} / u_{\mathrm{v}}$.

In presenting $u_{\mathrm{e}}$ and $u_{\mathrm{v}}$ by equation [23]

$$
u_{\mathrm{i}}=3 \mathrm{e} D_{\mathrm{i}} / 2 k_{\mathrm{B}} T
$$

we are transforming (31) to

$$
R \sim 9 M_{\mathrm{o}} K D_{\mathrm{v}} a_{0} / 32 h,
$$

where $D_{\mathrm{v}}$ is presented by [24] as the temperature dependence

$$
D_{\mathrm{v}}=1.50 \times 10^{-6} \exp \left(-1.28 / k_{\mathrm{B}} T\right),
$$

does (35) equal to (19) for $h=1 \mathrm{mkm}$.

Thus, growing the oxide scale on the zirconium cladding of fuel elements is being defined by the product of electronic density on the $\mathrm{ZrO} / \mathrm{ZrO}_{2}$ interface and the mobility of oxygen vacancies in the dense $\mathrm{ZrO}_{2-x}$ layer. Decreasing any of them we will inhibit the oxide corrosion of zirconium cladding.

\section{Discussion of results}

After reaching the critical thickness of $2 \mathrm{mkm}$, DPOS breaks off from the zirconium cladding surface and the rate of metal corrosion dramatically increases as shown in Figure $3[5]$.

This process is known as the "breakaway" oxidation [5] due to opening the unprotected zirconium surface for oxidizers that increases the oxidative corrosion as shown in Figure 3. At the same time, the mechanism of such the breakaway so far is under debate in the scientific literature and the effect of additives on this process is not understood.

Since the oxidation rate (35) depends on the maximal electronic density in DPOS (at $\varepsilon_{\mathrm{Fz}}$ ) and the mobility of oxygen vacancies there, it is necessary to inhibit the electronic conductivity in the oxide scale and to decrease the mobility of oxygen vacancies. It can be practiced by adding a metal of lesser valence than zirconium [8]. Such the addition stabilizes a high-temperature cubic phase of zirconia as the solid electrolyte with electronic conductivity practically equal to zero $[13,25]$. 


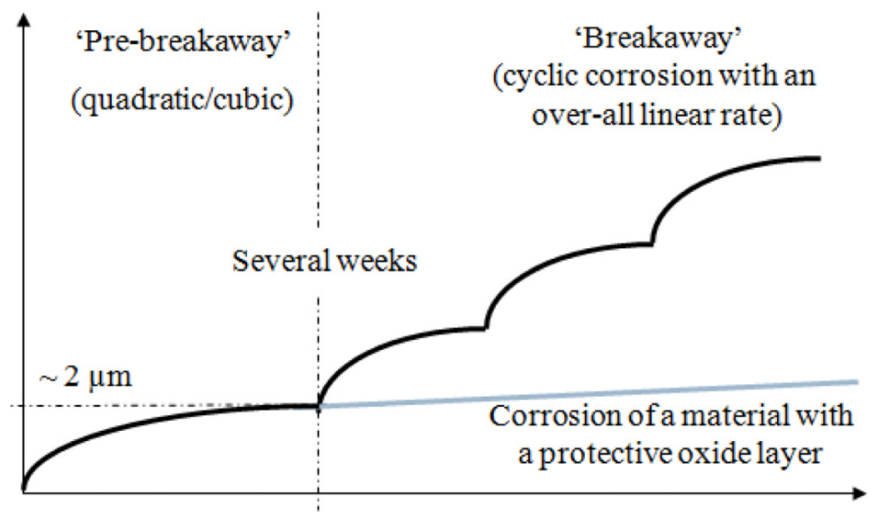

Fig. 3. The zirconium oxidation; the blue line shows the weight gain that would be expected for a material with a protective barrier layer which breaks down and cyclic oxidation is characterized by the overall linear growth [5].

For yttrium-stabilized zirconia (YSZ) at its addition of $\leq 9 \mathrm{~mol} \%$, there is no positive effect because the band gap is the same $(\sim 4.0 \mathrm{eV})$ and the molar density of electrons in the oxide scale is in the same range of $10^{21}$ to $10^{10} \mathrm{~mol}^{-1}$ (see above) at $650 \mathrm{~K}$ but the molar density of oxygen vacancies is very high $\sim 10^{22} \mathrm{~mol}^{-1}[26]$.

In contrast, $\varepsilon_{\mathrm{g}}$ of calcium-stabilized zirconia (CSZ) is equal to $\sim 5.6 \mathrm{eV}[25]$ at $\leq 15 \mathrm{~mol} \%$ of the additive that inhibits the electronic conductivity in the oxide scale for the same $\mu_{\mathrm{o}}(T)(9)$ and the dimensionless content $x_{\mathrm{s}} \sim 0.1$ of oxygen vacancies because $\varepsilon_{\mathrm{Fz}}(13)$ becomes appreciably lower than $\varepsilon_{\mathrm{c}}=-1.2 \mathrm{eV}$ (see Fig. 4 in comparison with Fig. 2):

$$
\varepsilon_{\mathrm{Fz}}=-2.28+1.08 k_{\mathrm{B}} T \text {. }
$$

One can find from (10) and (37) that at $650 \mathrm{~K}$, the maximal density of electrons in CSZ is less than $10^{16} \mathrm{~mol}^{-1}$.

Then, one can find $a_{0}=2.94 \exp \left(-1.08 / k_{\mathrm{B}} T\right)$ by using equations (10) and (32)-(37). For the ratio $a_{0}(\boldsymbol{v}+1) \gg 4 x_{\mathrm{o}}$, we will obtain $R(T)$ at zirconium oxidation via CSZ layer of $1 \mathrm{mkm}$ in the form

$$
R=7.03 \times 10^{4} \exp \left(-2.36 / k_{\mathrm{B}} T\right) .
$$

By comparing this equation with (19), one can conclude that the oxidation rate of zirconium cladding with the surface thin layer of the alloy, $\mathrm{Zr}-\mathrm{Ca}(15 \%)$, on a few orders of magnitude less than the usual zirconium oxidation. Then, the oxide scale on such the cladding of fuel elements in PWR will grow up to $2 \mathrm{mkm}$ during $10^{5} \mathrm{~h}$ instead of $10^{3} \mathrm{~h}$ for the up-to-date cladding.

Obviously, this should be checked by a corrosion test of such cladding.

\section{Conclusions}

The electronic model of the oxide scale on zirconium cladding of the fuel elements in PWR is developed for studying the role of electrons in the zirconium oxidation by the aqueous coolant.

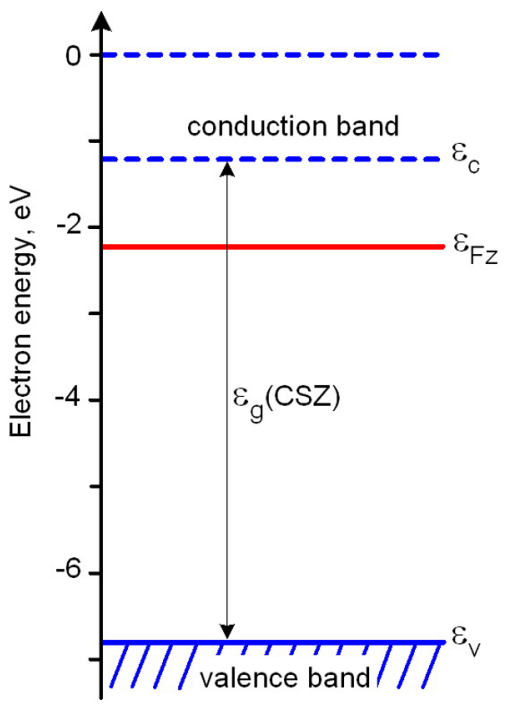

Fig. 4. The electronic band structure of CSZ with Fermi level, $\varepsilon_{\mathrm{Fz}}$, (red line) expressed by equation (37) for $650 \mathrm{~K}$.

The concentrations correlation of electrons and oxygen vacancies in forming the hypo-stoichiometric zirconia on the zirconium cladding transforms zirconia into a mixed conductor. However, the higher mobility of electrons in this conductor does their concentration by the dominant factor in zirconium oxidation.

The two-layer oxide scale is the result of the action of double electric layer in the $\mathrm{Zr} / \mathrm{ZrO}_{2-x}$ interface which enriches $\mathrm{ZrO}_{2-x}$ by oxygen vacancies up to forming the black zircon, $\mathrm{ZrO}$, and facilitates the penetration of zirconium atoms into this layer.

It is possible that the oxidation rate may be inhibited by decreasing the electronic conductivity in the oxide scale. For this, calcium should be implanted into the near-surface layer of zirconium cladding for forming the calciumstabilized zirconia on its surface.

\section{Nomenclature}

$\mathrm{e}^{-} \quad$ electron charge (e)

$\left[\mathrm{e}^{-}\right]$the molar concentration of electrons in $\mathrm{ZrO}_{2-x}$ $\left(\mathrm{mol}^{-1}\right)$

$h$ the thickness of $\mathrm{ZrO}_{2-x}$ in the dense part of oxide scale $(\mathrm{m})$

$j_{\mathrm{i}} \quad$ the specific current of $i$-particles $\left(\mathrm{e} / \mathrm{m}^{2} \mathrm{~s}\right)$

$K \quad$ the dimensional unit $\left(4.61 \times 10^{4} \mathrm{~mol} / \mathrm{m}^{3}\right)$

$k_{\mathrm{B}} \quad$ Boltzmann constant $\left(8.62 \times 10^{-5} \mathrm{eV} / \mathrm{K}\right)$

$L_{\mathrm{D}} \quad$ Debye length of oxygen vacancies $(\mathrm{nm})$

$M_{\mathrm{o}} \quad$ the zirconia molar mass $(0.123 \mathrm{~kg} / \mathrm{mol})$

$N_{\mathrm{A}} \quad$ Avogadro number $\left(6.02 \times 10^{23} \mathrm{~mol}^{-1}\right)$

$n_{\mathrm{e}} \quad$ the volume concentration of electrons in $\mathrm{ZrO}_{2-x}$ equal to $K\left[\mathrm{e}^{-}\right]\left(\mathrm{m}^{-3}\right)$

$n_{\mathrm{v}} \quad$ the volume concentration of oxygen vacancies in $\mathrm{ZrO}_{2-x}$ equal $K\left[\mathrm{~V}_{\mathrm{O}}^{2+}\right]\left(\mathrm{m}^{-3}\right)$

$P_{\mathrm{O}_{2}} \quad$ the equivalent oxygen pressure (MPa)

$P_{\mathrm{O}_{2}(\mathrm{Zr})}$ the same for zirconia dissociation

$R^{2}$ the oxidation rate of zirconium in water $\left(\mathrm{kg} / \mathrm{m}^{2} \mathrm{~s}\right)$

$T \quad$ Kelvin temperature $(\mathrm{K})$

$u_{\mathrm{i}} \quad$ the mobility of $i$-particle $\left(\mathrm{m}^{2} / \mathrm{s} \mathrm{V}\right)$ 
$\mathrm{V}_{\mathrm{O}}^{2+}$ the charged oxygen vacancy in hypo-stoichiometric zirconia, $\mathrm{ZrO}_{2-x}(\mathrm{e})$

$\left[\mathrm{V}_{\mathrm{O}}^{2+}\right]$ the molar concentration of oxygen vacancies in $\mathrm{ZrO}_{2-x}\left(\mathrm{~mol}^{-1}\right)$

$x \quad$ the dimensionless degree of $\mathrm{ZrO}_{2-x}$ non-stoichiometry: $(x<0)$ for hyper-stoichiometric state and $(x>0)$ for the hypo-stoichiometric one

$x_{\mathrm{o}} \quad$ a background non-stoichiometry $\left(\sim 10^{-5}\right)$

$x_{\mathrm{s}} \quad$ the dimensionless content of oxygen vacancies off the metal additive

$y \quad$ the coordinate in the layer of $\mathrm{ZrO}_{2-x}(\mathrm{~m})$

$\alpha \quad$ the dielectric parameter of zirconia $\left(1.74 \mathrm{eV} / \mathrm{nm}^{2}\right)$

$\varepsilon_{\mathrm{c}} \quad$ the bottom of conduction band $(\mathrm{eV})$

$\varepsilon_{\mathrm{F}} \quad$ Fermi level in the band gap of non-stoichiometric dioxide $(\mathrm{eV})$

$\varepsilon_{\mathrm{g}} \quad$ the band gap of dioxide $(\mathrm{eV})$

$\varepsilon_{\mathrm{v}} \quad$ the top of valence band $(\mathrm{eV})$

$\Delta_{\mathrm{dl}} \quad$ the potential of double electric layer $(\mathrm{V})$

$\mu_{\mathrm{o}}(T)$ the electrochemical potential of stoichiometric zirconia $(\mathrm{eV})$

$\mu_{\mathrm{v}}(x) \quad$ the electrochemical potential of oxygen vacancies in hypo-stoichiometric $\mathrm{ZrO}_{2-x}$ as a function of $x$ $(\mathrm{eV})$

$\varphi \quad$ the electric potential in double layer $(\mathrm{V})$

$\chi_{\mathrm{o}} \quad$ the work function of stoichiometric dioxide $(\mathrm{eV})$

$\chi \quad$ the work function of non-stoichiometric dioxide $(\mathrm{eV})$

The authors would like to thank their colleagues for active discussion on the aspects of electronic model in growing the oxide scale on zirconium cladding of fuel elements for PWR.

\section{References}

1. D. Hudson et al., in Proceedings of the 14th International Conference on Environmental Degradation of Materials in Nuclear Power Systems, Virginia Beach (2009), p. 1407

2. B. Jungblut, G. Sicking, T. Papachristos, Surf. Interface Anal. 13, 135 (1988)
3. C. Morant et al., Surf. Sci. 218, 331 (1989)

4. H. Gohr et al., in Proceedings of the 11th International Symposium of American Society for Testing and Materials (ASTM STP 1295) (1996), p. 181

5. C. Lemaignan, in ASM Handbook on Corrosion: Environments and Industries, edited by S.D. Cramer, B.S. Covino (ASM International, Ohio, 2006), Vol. 13C

6. V.N. Shishov et al., J. ASTM Int. 5, 01 (2008)

7. J.P. Foster, H.K. Yueh, R.J. Comstock, J. ASTM Int. 5, $01(2008)$

8. P.N. Alekseev, A.L. Shimkevich, in Proceedings of the Conference on Reactor Fuel Performance (TopFuel 2015), Zurich (2015), Poster, p. 387

9. B. Cox, J. Nucl. Mater. 336, 331 (2005)

10. M. Inagaki, M. Kanno, H. Maki, in Proceedings of the 9th International Symposium of American Society for Testing Materials (ASTM STP 1132) (1990), p. 437

11. N. Ni et al., Scr. Mater. 62, 564 (2010)

12. I. Barin, Thermochemical data of pure substances (V.C.H., Weinheim, 1989)

13. H. Frank, J. Nucl. Mater. 306, 85 (2002)

14. V.V. Osiko, A.L. Shimkevich, B.A. Shmatko, Lect. Acad. Sci. USSR 267, 351 (1982)

15. M.M. Nasrallah, D.L. Douglass, Oxid. Met. 9, 357 (1975)

16. R.W. Vest, N.M. Tallan, J. Appl. Phys. 36, 543 (1965)

17. N. Ni et al., Ultramicroscopy 111, 123 (2011)

18. Ch. Kittel, Introduction to solid state physics, 8th edn. (Wiley, New York, 2004), p. 20

19. Information on http://environmentalchemistry.com/yogi/ periodic/Zr.html

20. V.A. Blokhin, Yu.A. Musikhin, A.L. Shimkevich, Institute for Physics and Power Engineering Preprint No. 1832 (1987)

21. R.A. Causey, D.F. Cowgill, B.H. Nilson, Report SAND2005-6006, Sandia National Laboratories, 2005

22. C. Wagner, Z. Phys. Chem. B21, 25 (1933)

23. S. Lindsay, Introduction to nanoscience (OUP, Oxford, 2009)

24. A.G. Belous et al., Inorg. Mater. 50, 1235 (2014)

25. V.N. Chebotin, M.V. Perphiljev, Electrochemistry of solid electrolytes (Chemistry, Moscow, RF, 1978)

26. T. Shimonosono et al., Solid State Ionics 225, 61 (2012)

Cite this article as: Pavel N. Alekseev, Alexander L. Shimkevich, A role of electrons in zirconium oxidation, EPJ Nuclear Sci. Technol. 3, 19 (2017) 